\title{
Influence of the Isomeric Structures of Butyl Acrylate on Its Single-Electron Transfer-Degenerative Chain Transfer Living Radical Polymerization in Water Catalyzed by $\mathrm{Na}_{2} \mathrm{~S}_{2} \mathrm{O}_{4}$
}

\author{
JORGE F. J. COELHO, ${ }^{1,2}$ ERICA Y. CARVALHO, ${ }^{2}$ DINA S. MARQUES, ${ }^{2}$ \\ ANATOLIY V. POPOV, ${ }^{3}$ VIRGIL PERCEC, ${ }^{4} \mathrm{M}$. H. $\mathrm{GIL}^{2}$ \\ ${ }^{1}$ Centre of Ophthalmology, Biomedical Institute for Research in Light and Image (IBILI), \\ Faculty of Medicine, University of Coimbra, 3000-354 Coimbra, Portugal \\ ${ }^{2}$ Department of Chemical Engineering, University of Coimbra, Pólo II, Pinhal de Marrocos, \\ 3030-290 Coimbra, Portugal \\ ${ }^{3}$ Department of Radiology, University of Pennsylvania, Philadelphia, Pennsylvania 19104-6323 \\ ${ }^{4}$ Roy and Diana Vagelos Laboratories, Department of Chemistry, University of Pennsylvania, Philadelphia, Pennsylvania
}

Received 20 May 2008; accepted 10 July 2008

DOI: 10.1002 / pola.22963

Published online in Wiley InterScience (www.interscience.wiley.com).

\begin{abstract}
The aim of this work is to the study the influence of the isomer structures of butyl acrylate monomer on the single-electron transfer/degenerative chain transfer mediated living radical polymerization (SET-DTLRP). The kinetic of isobutyl acrylate is determined for the first time by SET-DTLRP in water catalyzed by sodium dithionite. The plots of number-average molecular weight versus conversion and $\ln \left([\mathrm{M}]_{0} /[\mathrm{M}]\right)$ versus time are linear, demonstrating a controlled polymerization. The influence of the isomer $t$-butyl, $i$-butyl, and $n$-butyl on the kinetics, properties, and stereochemistry of the reactions was assessed. To the best of our knowledge, there is no previous report dealing with the synthesis of PiBA by any LRP approach in aqueous medium. The results presented in this work suggest that the stability provided by the acrylate side group has an important influence in the polymerization process. (1) 2008 Wiley Periodicals, Inc. J Polym Sci Part A: Polym Chem 46: 6542-6551, 2008

Keywords: degenerative chain transfer; $i$-butyl acrylate; kinetics (polym.); living polymerization; living radical polymerization (LRP); $n$-butyl acrylate; single-electron transfer; $t$-butyl acrylate; telechelics
\end{abstract}

\section{INTRODUCTION}

Living radical polymerization (LRP) is one of the most powerful routes to prepare well-tailored-

Correspondence to: Jorge F. J. Coelho (E-mail: jcoelho3@ eq.uc.pt)

Journal of Polymer Science: Part A: Polymer Chemistry, Vol. 46, 6542-6551 (2008) ๑ 2008 Wiley Periodicals, Inc. made architectures that fit emerging applications. This strategy joins the exceptional flexibility and potential of the living approaches with the radical polymerization advantages. The most common strategies include reversible addition fragmentation chain transfer (RAFT), ${ }^{1}$ nitroxide-mediated living radical polymerization (NMP), ${ }^{2}$ and metalcatalyzed living radical polymerization. ${ }^{3}$ Because of the remarkable interest from the academia and 
industrial world, the different methods have witnessed important developments over the last decade. The reaction conditions become more attractive and easy to perform in the industrial environment. On this matter, the development of a new strategy based on reversible activation-deactivation step required to accomplish LRP by combination of competitive single-electron transfer and degenerative chain transfer mediated living radical polymerization (SET-DTLRP) ${ }^{4}$ is a clear example. Discovered by Percec, Popov et al. ${ }^{4-6}$ this strategy has proved to be effective in the polymerization of activated $^{7,8}$ and nonactivated monomers. ${ }^{4-6,9-12}$

The synthesis of poly(alkyl acrylates) has industrial advantages because they can cover a large range of mechanic and thermal properties through the variation of alkyl substitute group. They have numerous industrial applications, including surfactants, compatibilization agents in polymer blends, adhesives, additives in highimpact materials, and thermoplatic elastomers. ${ }^{13}$

Specifically, the polymers of butyl acrylate ( $n$-butyl, $t$-butyl, and $i$-butyl) are used in an enormous range of applications, such as adhesives, coatings, because of its low glass transition temperature and high durability. These monomers are also used in the attainment of block copolymers composed of hard segments (PMMA or PS) and rubbery blocks (PtEHA, PnBA, $\mathrm{P} t \mathrm{BA}$, or $\mathrm{P} i \mathrm{BA})$. These materials can find use in a number of applications such as thermoplastic elastomers or compatibilizers of polymer blends. This potential justifies the growing interest in the development of new methodologies that allow the control over the final structure. However, because of the high reactivity, in particular due to a high tendency of side reactions in polyacrylates, ${ }^{14}$ the control over the polymerization is difficult to be achieved.

In the field of the isomers of butyl acrylate monomers synthesized by LRP, Vlcek et al. ${ }^{14}$ reported the synthesis of diblock copolymers of methyl methacrylate (MMA) with $t$-butyl and $n$-butyl acrylates by anionic polymerization. The reaction conditions were particularly stringent, such as the use of ligands with a high stabilizing efficiency in toluene/THF mixture, at $-78{ }^{\circ} \mathrm{C}$. Ibrahim et al. ${ }^{15}$ reported the synthesis of $t$-butyl acrylate by atom transfer radical polymerization (ATRP) using $\mathrm{FeCl}_{2} \cdot 4 \mathrm{H}_{2} \mathrm{O}\left(\mathrm{PPh}_{3}\right)_{2}$ as catalyst system in conjunction with methyl 2-bromopropionate as initiator, in bulk and in solution using acetone as a solvent. Bussels et al. ${ }^{16,17}$ described the

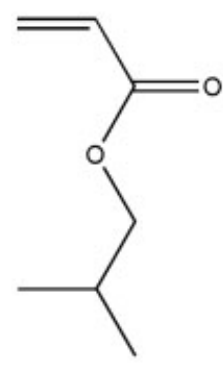

isobutyl acrylate

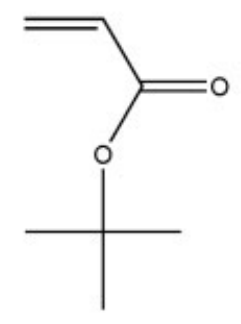

tert - butyl acrylate

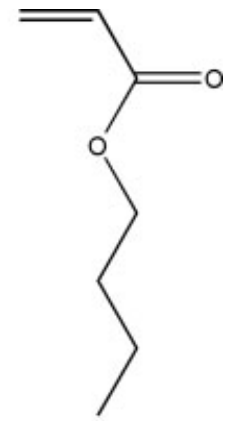

butyl acrylate
Figure 1. Isomeric structures of butyl acrylate.

homopolymerization and the copolymerization of $n$-butyl and other acrylates by RAFT in solution and in aqueous dispersions. Muñoz-Bonilla et al. ${ }^{13}$ reported the synthesis of homo and copolymers of $t$-butyl and $i$-butyl acrylates by ATRP. The homopolymerizations of $t$-butyl and $i$-butyl acrylates were carried in bulk with dimethyl 2,6-dibromoheptanedioate (DMBHD) as a difunctional initiator at $70{ }^{\circ} \mathrm{C} .{ }^{13} \mathrm{~A}$ common characteristic is present in the different strategies described earlier, which is related to the stringent conditions of the reactions set and the hazard solvents used. This feature avoids the widespread of these techniques in large-scale productions giving a final product with reasonable prices.

On this matter, the SET-DTLRP has a great importance from the scientific, technological, and environmental standpoints. This approach have presented promising results in its industrial implementation leading to flexible materials that are able to replace some commercialized products that are made from a thermoplastic blended with free plasticizers, ${ }^{12,18-20}$ which is able to predict its commercialization in large production in shorttime period. The SET-DTLRP allowed for the first time the preparation of flexible PVC-based materials free of plasticizers. ${ }^{19,20}$ The complete understanding of the mechanisms and features of the SET-DTLRP is of prime importance to accelerate the commercialization.

The aim of this work is to study the influence of the isomeric structures of the butyl groups (Fig. 1) on SET-DTLRP carried out in water, catalyzed by sodium dithionite. To the best of our knowledge, there are no reports about the synthesis of $\alpha, \omega$-di(iodo)PiBA macroinitiators in aqueous medium that can be further modified. The complete understanding and manipulation of the LRP reaction conditions to resemble those to the 
conventional radical process is of outstanding importance to accelerate the large-scale commercialization of these new acrylic-based materials.

\section{EXPERIMENTAL}

\section{Materials}

The tetrahydrofuran HPLC-grade uninhibited, alumina oxide, iodoform (99\%), sodium dithionite $(85 \%)$, sodium bicarbonate (99\%), isobutyl acrylate, and $t$-butyl acrylate were purchased from Sigma-Aldrich. Monomers were purified through a basic $\mathrm{Al}_{2} \mathrm{O}_{3}$ column before using. $p$-Toluenesulfinic acid, sodium salt, hydrate (pTsNa) (98\%) were purchased form Acros Organics. The polystyrene standards for TriSEC measurements were purchased from Polymer Laboratories. The hydroxypropyl methylcellulose-Methocel F50 (MF50) was purchased from Dow Chemical Company. The partially hydrolyzed poly(vinyl alcohol) (PVA) was purchased from Syntomer. The other compounds were ordered from Sigma-Aldrich and used as received.

\section{Polymerization of iBA via SET/DTLRP}

The typical procedure was performed as described (example ratio $[i \mathrm{BA}] /\left[\mathrm{CHI}_{3}\right]=100$ ). A $50-\mathrm{mL}$ Ace Glass $8645 \# 15$ pressure tube equipped with bushing and plunger valve was charged with $9 \mathrm{~mL}$ of deionized water, $48.3 \mathrm{mg}$ of a $3 \%$ PVA solution (490 ppm), and $33.40 \mathrm{mg}$ of a $1.86 \%$ MF50 solution $(210 \mathrm{ppm})$. The content was stirred and bubbled with nitrogen during $10 \mathrm{~min}$. The other compounds were then weighed, such as catalyst $\left(\mathrm{Na}_{2} \mathrm{~S}_{2} \mathrm{O}_{4}, 146.7 \mathrm{mg}, 0.84 \mathrm{mmol}\right)$, initiator $\left(\mathrm{CHI}_{3}\right.$, $82.9 \mathrm{mg}, 0.21 \mathrm{mmol})$, buffer $\left(\mathrm{NaHCO}_{3}, 146.7 \mathrm{mg}\right.$, $0.84 \mathrm{mmol}$ ), additive (pTsNa, $82.7 \mathrm{mg}, 0.42 \mathrm{mmol}$ ) and $3 \mathrm{~mL}(2.1 \mathrm{mmol})$ of purified $i \mathrm{BA}$, and added into the tube. The tube was closed, frozen in $\mathrm{MeOH} /$ dry ice and degassed through the plunger valve by applying circles of reduced pressure followed by filling the tube with inert gas for 20 times at $-40{ }^{\circ} \mathrm{C}$. The valve was closed and the reaction was kept in a controlled temperature water bath for $1 \mathrm{~h}$ at $35{ }^{\circ} \mathrm{C}$ under stirring. At the end of the reaction, a small liquious part was taken for TriSEC measurements. The polymer was placed in a preweighted vial, and the remaining part of the tube was carefully washed with THF and placed in a different vial. After drying in a vacuum oven until constant weight, both vials were weighted to determine the final conversion $(62 \%)$.

\section{Polymerization of $\boldsymbol{t B A}$ via SET/DTLRP}

The synthesis of $\mathrm{P} t \mathrm{BA}$ was carried out following the same experimental procedure described earlier for PiBA.

\section{Characterization Techniques}

The chromatography parameters of the samples were determined using a HPSEC; Viscotek (Dual detector 270, Viscotek, Houston, USA) with a differential viscometry (DV); right angle laser lightscattering (RALLS, Viscotek) and RI (Knauer K-2301). The column set consisted of a PL $10 \mu \mathrm{m}$ guard column $(50 \mathrm{~mm} \times 7.5 \mathrm{~mm})$ followed by two MIXED-B PL columns $(300 \mathrm{~mm} \times 7.5 \mathrm{~mm}, 10$ $\mu \mathrm{m})$. HPLC pump (Knauer K-1001) was set with a flow rate of $1 \mathrm{~mL} / \mathrm{min}$. The eluent (THF) was previously filtered through a $0.2-\mu \mathrm{m}$ filter. The system was also equipped with a Knauer on-line degasser. The tests were done at $30{ }^{\circ} \mathrm{C}$ using an Elder CH-150 heater. Before the injection (100 $\mu \mathrm{L}$ ), the samples were filtered through a PTFE membrane with $0.2 \mu \mathrm{m}$ pore. The system was calibrated with narrow polystyrene standards. The differential refractive index of $\mathrm{P} i \mathrm{BA}$ and $\mathrm{P} t \mathrm{BA}$ for $670 \mathrm{~nm}$ were determined $(\mathrm{d} n / \mathrm{d} c=0.056$ and $\mathrm{d} n /$ $\mathrm{d} c=0.064$, respectively). The analysis of lightscattering data by Viscotek's software was done by assuming that the second virial coefficient was zero, considering the low solution concentrations used in this work. The ${ }^{1} \mathrm{H}$ NMR spectra (500 $\mathrm{MHz}$ ) were recorded in a Bruker DRX 500 spectrometer at $32{ }^{\circ} \mathrm{C}$ in $\mathrm{CDCl}_{3}$ with tetramethylsilane (TMS) as an internal standard. Diad tacticities of the polymer were determined from ${ }^{1} \mathrm{H}$ NMR as it was described elsewhere. ${ }^{21}$

\section{RESULTS AND DISCUSSION}

The rate constant of propagation is affected not only by the reactivity of the monomer and the growing radical (active center) but also by polar and electronic effects. Generally, more reactive monomers form less reactive radicals; a decrease in the monomers reactivity is accompanied by a stronger increase in the resulting radical reactivities. These radicals do not bear charge, however they can be polarized, and comprise electrophilic or nucleophilic character. Active species have the predominant influence on the rate constants of radical propagation, the structure of the monomer being less important. ${ }^{22}$ 
a) $[\mathrm{iBA}]_{0} /\left[\mathrm{CH}_{3}\right]_{0} /\left[\mathrm{Na}_{2} \mathrm{~S}_{2} \mathrm{O}_{4}\right]_{0} /[\mathrm{pTsNa}] /\left[\mathrm{NaHCO}_{3}\right]_{0}=100 / 1 / 4 / 2 / 1.45,35^{\circ} \mathrm{C}$

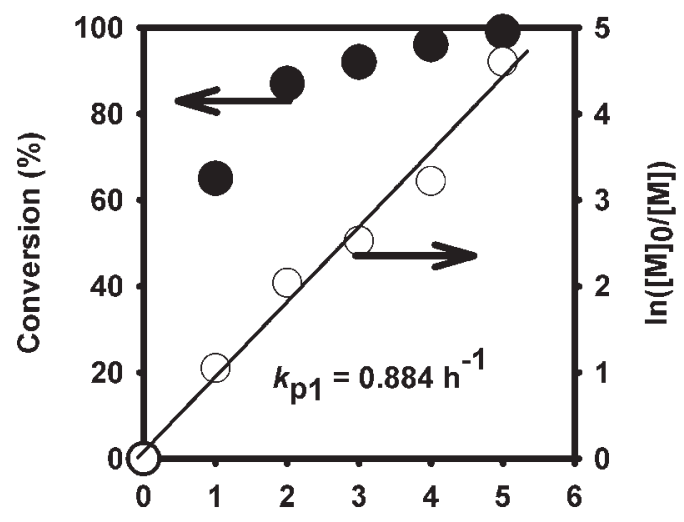

Time (h)

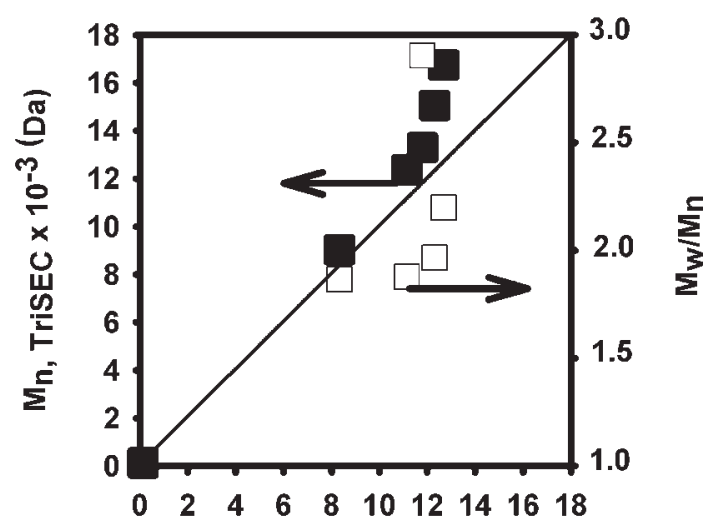

$M_{\text {th }}$, TriSEC $\times 10^{-3}(\mathrm{Da})$

b) $[\mathrm{iBA}]_{0} /\left[\mathrm{CHI}_{3}\right]_{0} /\left[\mathrm{Na}_{2} \mathrm{~S}_{2} \mathrm{O}_{4}\right]_{0} /[\mathrm{pTsNa}] /\left[\mathrm{NaHCO}_{3}\right]_{0}=250 / 1 / 4 / 2 / 1.45,35^{\circ} \mathrm{C}$
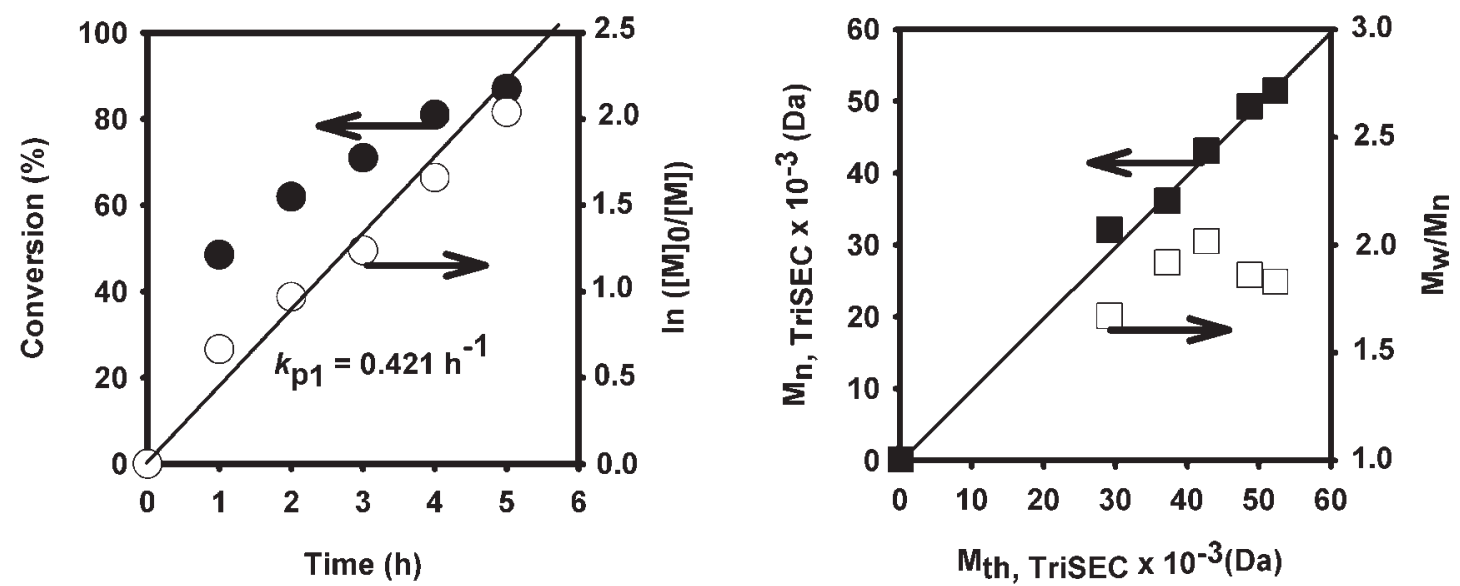

Figure 2. (a) The kinetic plots for $\mathrm{Na}_{2} \mathrm{~S}_{2} \mathrm{O}_{4} / \mathrm{NaHCO}_{3}$-catalyzed LRP of $i \mathrm{BA}$ prepared at $35{ }^{\circ} \mathrm{C}$ for the following conditions: $[i \mathrm{BA}]_{0} /\left[\mathrm{CHI}_{3}\right]_{0} /\left[\mathrm{Na}_{2} \mathrm{~S}_{2} \mathrm{O}_{4}\right]_{0} /[\mathrm{pTsNa}]_{0} /$ $\left[\mathrm{NaHCO}_{3}\right]_{0}=100 / 1 / 4 / 2 / 1.45(\mathrm{~mol} / \mathrm{mol} / \mathrm{mol} / \mathrm{mol}) ;[$ MethocelF50]/[PVA 88$]=210 / 490$ (ppm/ppm, w/w relative to iBA); (b) the kinetic plots for $\mathrm{Na}_{2} \mathrm{~S}_{2} \mathrm{O}_{4} / \mathrm{NaHCO}_{3}$-catalyzed LRP of $i \mathrm{BA}$ prepared at $35^{\circ} \mathrm{C}$ for the following conditions: $[i \mathrm{BA}]_{0} /\left[\mathrm{CHI}_{3}\right]_{0} /\left[\mathrm{Na}_{2} \mathrm{~S}_{2} \mathrm{O}_{4}\right]_{0} /$ $[\mathrm{pTsNa}]_{0} /[\mathrm{NaHCO}]_{0}=250 / 1 / 4 / 2 / 1.45(\mathrm{~mol} / \mathrm{mol} / \mathrm{mol} / \mathrm{mol}) ;[$ MethocelF50]/[PVA 88] $=$ $210 / 490$ ( $p p m / p p m, w / w$ relative to $\mathrm{BBA})$.

To compare the kinetics of the three isomers of butyl acrylate by SET-DTLRP, the synthesis of PiBA was carried out for the first time using the same experimental conditions reported earlier. ${ }^{11}$

The kinetics experiments shown in Figure 2 were obtained gravimetrically according to the procedure described (vide infra).

The data representation of $\ln \left([\mathrm{M}]_{0} /[\mathrm{M}]\right)$ versus polymerization time shows only one slope, suggesting that after $6 \mathrm{~h}$ of reaction the monomer diffusion was still not limited by the viscosity of the reaction mixture. Moreover, the results suggest a linear dependence of the molecular weight determined by TriSEC $\left(M_{\mathrm{n}, \text { TriSEC }}\right)$ versus the theoretical molecular weight $\left(M_{\text {nth }}\right)$. The living character of SET-DTLRP of $i \mathrm{BA}$ is therefore supported by these two features. As expected, the reaction rate decreases with the ratio [monomer]/[initiator] because of a reduced number of radicals for high DPs. Regardless of the DP value, the polymerization reactions data exhibit first-order kinetics relatively to the monomer concentration. 
Table 1. The Kinetic Constants for All Butyl Polymers in a Range of DPs from 100 and 250

\begin{tabular}{lllllllll}
\hline & \multicolumn{2}{c}{$\mathrm{P} n \mathrm{BA}^{11}$} & & \multicolumn{2}{c}{$\mathrm{P} i \mathrm{BA}$} & & \multicolumn{2}{c}{$\mathrm{P} t \mathrm{BA}$} \\
\cline { 2 - 3 } \cline { 7 - 8 } $\mathrm{nP}$ & $k_{\mathrm{p} 1}\left(\mathrm{~h}^{-1}\right)$ & $k_{\mathrm{p} 2}\left(\mathrm{~h}^{-1}\right)$ & & $k_{\mathrm{p} 1}\left(\mathrm{~h}^{-1}\right)$ & $k_{\mathrm{p} 2}\left(\mathrm{~h}^{-1}\right)$ & & $k_{\mathrm{p} 1}\left(\mathrm{~h}^{-1}\right)$ & $k_{\mathrm{p} 2}\left(\mathrm{~h}^{-1}\right)$ \\
\hline 100 & 0.9024 & 0.0159 & & 0.884 & - & & 1.13 & 0.21 \\
250 & 0.7742 & 0.0173 & & 0.421 & - & 0.748 & 0.059 \\
\hline
\end{tabular}

The same procedures were used to determine the reaction kinetics of $\mathrm{P} t \mathrm{BA}$ and under the same reactions conditions, the kinetic constants are presented in Table 1, and the kinetics data are compared in Figure 3.

According to the results presented in Table 1, the $\mathrm{P} t \mathrm{BA}$ exhibits the highest polymerization rate regardless the DP value considered followed by $\mathrm{P} n \mathrm{BA}$ and $\mathrm{P} i \mathrm{BA}$, indicating that the monomer $t$ BA presents the higher reactivity by SETDTLRP.

Theoretically in LRP, as the stability that side group $\mathrm{R}$ confers to iodine decreases, iodine is more easily removed and faster is the polymerization kinetic. The $\mathrm{R}$ group must stabilize the resulting radical by inductive and resonance effects. Therefore, based on the results, the tertbutyl group provides less stability to the resulting radical.

Considering the tendency observed for intrinsic viscosity data (Fig. 4), the less viscous polymer holds a side group that provides more stability to the propagating radical, exhibiting the slowest polymerization kinetics. Generally, a medium with reduced viscosity promotes less diffusion restrictions. For the same molecular weight, $\mathrm{P} t \mathrm{BA}$ shows the smallest radius of gyration; therefore, the radical of propagation may be less protected inducing a faster polymerization kinetics.

Nonetheless, this result is in agreement with the chain stiffness values of those polymers (see later). The stiffest polymer exhibit highest polymerization kinetics. On this matter, $\mathrm{P} t \mathrm{BA}$ is the stiffest polymer, followed by $\mathrm{P} n \mathrm{BA}$ and $\mathrm{P} i \mathrm{BA}$.

Contrary to PiBA, all the other butyl acrylate polymers exhibit two different slopes on the $\ln \left([\mathrm{M}]_{0} /[\mathrm{M}]\right)$ versus polymerization time for low DP values. The first slope, characterized by $k_{\mathrm{p} 1}$, represents the region where monomer diffusion is not limited by the viscosity of the reaction mixture. As the polymerizations proceeds trough time, there is an increase on the reaction mixture viscosity resulting from an increase in conversion which leads to the formation of a solid phase. This event is characterized by a second kinetic constant $k_{\mathrm{p} 2}$, being several times lower than $k_{\mathrm{p} 1}$. For the highest concentrations of monomers there is a tendency for the disappearance of the two different kinetics behaviors. ${ }^{11}$ Moreover, as the DP values increase, the difference between the two slopes decreases, independent of its absolute values. The influence of the molecular weight in the reactivity of the radical should be taken into account to explain this relation.

Concerning the polydispersity, a measure of the range of molecular weigh distributions is rather high in all experiences for each butyl polymer because of the heterogeneity of the medium. By definition, a living system is characterized by the absence of any breaking reaction chain and is not a synonym of low polydispersity like many authors assert. ${ }^{12,18-20}$ The preparation of a polymer with narrow molecular weights distributions, where polydispersivity decreases with conversion, implies a set of requirements very specific toward a particular system. Namely, the chain transfer or termination should be negligible; the rate of propagation should be higher than the rate of depropagation; the rate of initiation should be as fast as the rate of propagation; the equilibrium created between the different species involved in the reaction that also have different reactivities should be fast; and the system should be homogeneous with vigorous stirring. ${ }^{23,24}$

\section{SET-DTLRP of BA Isomers Initiated from $\alpha, \omega$-Di(iodo)poly(butyl acrylate) Isomers (Reinitiation Experiments)}

A living polymerization is a chain-growth reaction that proceeds in the absence of the kinetics steps of chain transfer or termination. The resulting polymers retain their chain-end activity and yield long linear chain macromolecules that can break and recombine reversibly, being in dynamic 
a) [lsomer $\mathrm{BA}]_{0} /\left[\mathrm{CH}_{3}\right]_{0} /\left[\mathrm{Na}_{2} \mathrm{~S}_{2} \mathrm{O}_{4}\right]_{0} /\left[\mathrm{NaHCO}_{3}\right]_{0}=100 / 1 / 4 / 1.45$

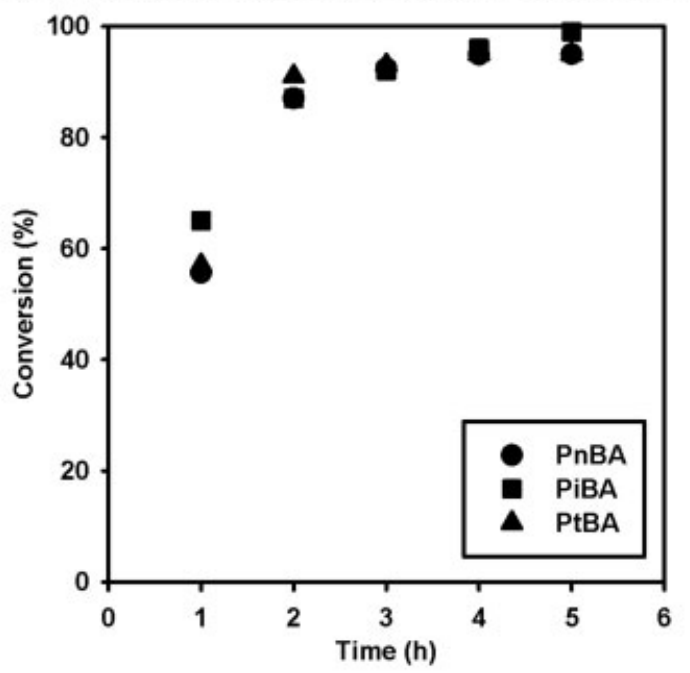

b) $[\text { ssomer } \mathrm{BA}]_{0} /\left[\mathrm{CH}_{3}\right]_{0} /\left[\mathrm{Na}_{2} \mathrm{~S}_{2} \mathrm{O}_{4}\right]_{0} /\left[\mathrm{NaHCO}_{3}\right]_{0}=250 / 1 / 4 / 1.45$

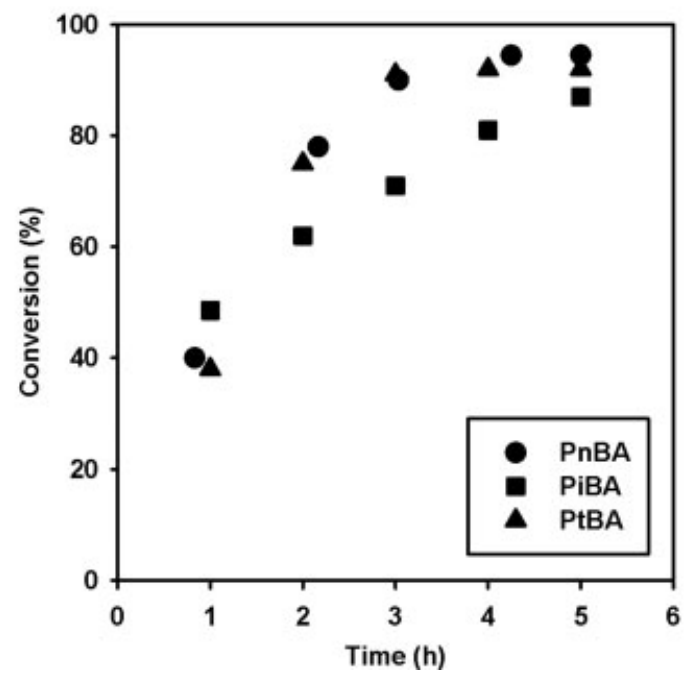

Figure 3. Conversion versus time of the $\mathrm{Na}_{2} \mathrm{~S}_{2} \mathrm{O}_{4} /$ $\mathrm{NaHCO}_{3}$-catalyzed LRP of 3 isomers of BA prepared at $35{ }^{\circ} \mathrm{C}$ for the following conditions: (a) [IsomerBA] $]_{0} /$ $\left[\mathrm{CHI}_{3}\right]_{0} /\left[\mathrm{Na}_{2} \mathrm{~S}_{2} \mathrm{O}_{4}\right]_{0} /[\mathrm{pTsNa}]_{0} /\left[\mathrm{NaHCO}_{3}\right]_{0}=100 / 1 / 4 / 2 /$ $1.45(\mathrm{~mol} / \mathrm{mol} / \mathrm{mol} / \mathrm{mol}) ;$ [MethocelF50]/[PVA 88] = $210 / 490(\mathrm{ppm} / \mathrm{ppm}, \mathrm{w} / \mathrm{w}$ relative to the monomer); (b) $[\text { IsomerBA }]_{0} /\left[\mathrm{CHI}_{3}\right]_{0} /\left[\mathrm{Na}_{2} \mathrm{~S}_{2} \mathrm{O}_{4}\right]_{0} /[\mathrm{pTsNa}]_{0} /[\mathrm{NaHCO} 3]_{0}$ $=250 / 1 / 4 / 2 / 1.45(\mathrm{~mol} / \mathrm{mol} / \mathrm{mol} / \mathrm{mol}) ;$ [MethocelF50]/ [PVA 88] $=210 / 490(\mathrm{ppm} / \mathrm{ppm}, \mathrm{w} / \mathrm{w}$ relative to the monomer).

equilibrium with respect to their molecular weight distribution. ${ }^{25}$

This technique allows preparation of macromonomers, macroinitiators, functional polymers, block and graft copolymers, and star polymers. ${ }^{22}$

The living character of the macroinitiators of PBA isomers prepared by SET-DTLRP were con- firmed by a reinitiation experiment that produced P $i \mathrm{BA}$ of $M_{\mathrm{n}, \text { TriSEC }}=85,320 \mathrm{Da}$ and $M_{\mathrm{w}} / M_{\mathrm{n}}=2.5$ after $12 \mathrm{~h}$ of reaction at $30{ }^{\circ} \mathrm{C}$ from the PiBA macroinitiator of $M_{\mathrm{n}, \operatorname{TriSEC}}=10,320, M_{\mathrm{w}} / M_{\mathrm{n}}=2.3$. The P $t$ BA of $M_{\mathrm{n}, \text { TriSEC }}=92,320 \mathrm{Da}$ and $M_{\mathrm{w}} / M_{\mathrm{n}}=$ 2.6 after $18 \mathrm{~h}$ of reaction at $30^{\circ} \mathrm{C}$ from the $\mathrm{P} t \mathrm{BA}$ macroiniciator of $M_{\mathrm{n}, \operatorname{TriSEC}}=13,450$.

Unlike conventional SEC technique, TriSEC configuration is a powerful tool for determining the molecular weights and MWD of polymers with high accuracy. The use of such multidetector allows uncovering chromatography parameters because of the distinctive principles of each detector and direct measurement of their signals. The most revealing parameters are intrinsic viscosity, [ $\eta$ ], and radius of gyration, $R_{\mathrm{g}}$, due to the establishment of correlations between them and the molecular weight. Intrinsic viscosity is a measure of the polymer contribution to the overall viscosity of the solution. $R_{\mathrm{g}}$ is a measure of molecular size and it is mathematically defined as the square root average of the distance of the molecular segments of the chain from its center of gravity. All this information combined together yield information on molecular structure of polymers, their conformation in solution, solubility in a given solvent, chain stiffness, and branching. Mark-HouwinkSakurada equation, MHS, is a well-known relationship that illustrates the variation of $[\eta]$ with $M_{\text {w,TriSEC }}$. Another correlation can be made by scaling this equation and correlate $R_{\mathrm{g}}$ with $M_{\mathrm{w} \text {,TriSEC }}$

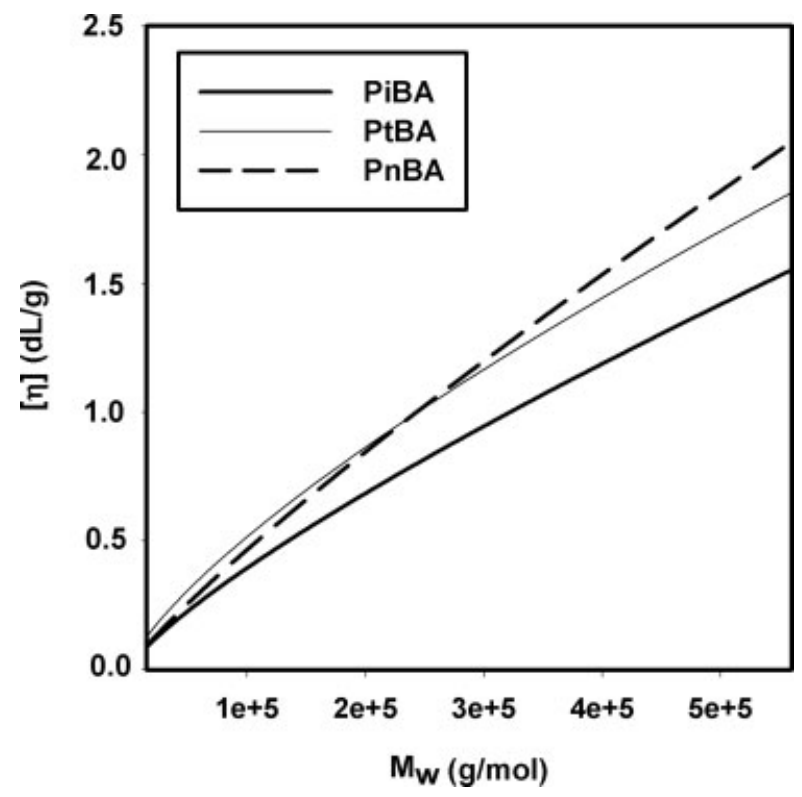

Figure 4. Intrinsic viscosity of the poly(butyl acrylate) isomers versus molecular weight. 
Table 2. MHS and $R_{\mathrm{g}}$ Scaling Relationship Constants for all Butyl Polymers

\begin{tabular}{lcccccc}
\hline & $K \times 10^{5}(\mathrm{dL} / \mathrm{g})$ & $\alpha$ & $R^{2}$ & $K^{\prime} \times 10^{3}(\mathrm{~nm})$ & $\alpha^{\prime}$ & $R^{2}$ \\
\hline $\mathrm{P} n B A^{\mathrm{a}}$ & 2.33 & 0.86 & 0.998 & 11.2 & 0.60 & 0.998 \\
$\mathrm{P} i \mathrm{BA}$ & 4.20 & 0.80 & 0.988 & 10.9 & 0.60 & 0.998 \\
$\mathrm{P} t \mathrm{BA}$ & 1.01 & 0.74 & 0.964 & 75.8 & 0.42 & 0.963 \\
\hline
\end{tabular}

${ }^{\text {a }}$ Data provided by ref. 11 .

(Table 2). These equations can be mathematically described as follows:

$$
\begin{gathered}
{[\eta]=K \times M^{\alpha}} \\
R_{\mathrm{g}}=K^{\prime} \times M^{\alpha^{\prime}}
\end{gathered}
$$

The exponential constant of both equations, $\alpha$ and $\alpha^{\prime}$, provide valuable information about conformation and solubility of polymers in solution.

The mathematical representation of the previous factors in the whole range of $M_{\mathrm{w}}$ analyzed reveals linear relations for all polymers, as observed in the correlation values obtained.

The determined values of the exponential constants, $\alpha$, made possible to perceive that $\mathrm{P} i \mathrm{BA}$ and P $t$ BA adopt a flexible chain in a theta solvent (0.78 and 0.74, respectively), whereas $\mathrm{P} n \mathrm{BA}$ appear to have a rigid chain in a good solvent (0.86). Actually, $\alpha$ is greater for a more extended conformation and this perception is reasonable because a polymer molecule with a greater dimension for a given contour length will experience a greater friction to move in the solvent. ${ }^{26}$ The comparison between MHS constant $\alpha$ of PBA isomers allowed to conclude that the solubility of these polymers in a given solvent diminishes as the pendent group became more branched.

Figure 4 shows the comparison between viscosities of PBA isomers for the same molecular weight.

For the same high molecular weight, PnBA exhibit a higher viscosity, followed by $\mathrm{P} t \mathrm{BA}$ and PiBA. At first, it would be expected to observe $\mathrm{P} t \mathrm{BA}$ as less viscous according to the nature of this structure. However, conformational factors must be conferring higher viscosity than expected.

Figure 5 compares the viscosity of PBA isomers prepared by SET and by FRP. The values proposed for MHS constants in the literature are different from those obtained in this work.

Predictably, for the same molecular weight, polymers produced by SET exhibit higher linearity, hence higher viscosity, especially for high molecular weights, than those prepared by $\mathrm{FRP}^{27}$ because of the perfect linearity of the polymer chains with the absence of side reactions. It is interesting to observe that the viscosity of the PiBA resemble the viscosity of the same polymer prepared by FRP. This result can be related to the lower reactivity of the monomer as concluded based on the results presented in this work.

The exponential constants, $\alpha^{\prime}$, obtained for $\mathrm{P} n \mathrm{BA}(0.6)$ and $\mathrm{P} i \mathrm{BA}(0.6)$ suggest that both polymers have a random coil conformation under theta conditions $(0.5)$ in a very good solvent. $\mathrm{P} t \mathrm{BA}$ exhibits a value of 0.42 , indicating a tendency for spherical conformation which is in accordance with its more compact structure.

The chain stiffness of the polymer chains was determined by evaluating the Flory's characteristic ratio, $C_{\infty}$, being mathematically defined as follows ${ }^{28,29}$ :

$$
C_{\infty}=\frac{\left\langle R_{\mathrm{g}}^{2}\right\rangle_{0}}{N \times l^{2}}
$$

where $\left\langle R_{\mathrm{g}}^{2}\right\rangle_{0}$ is the unperturbed mean-square endto-end distance of a polymer having $N$ main chain bonds of average length $1(0.154 \mathrm{~nm})$. The number of chain bonds is known by the molecular weight of the polymer, $M$, and molecular weight of the repeating unit, $m(N=2 \times \mathrm{M} / \mathrm{m})$. An auxiliary parameter entitle $K_{\theta}$, derived from the origin interception of Stockmayer-Fixman equation, $[\eta] \eta \mathrm{M}^{0.5}$ versus the $\mathrm{M}^{0.5}$, associate intrinsic viscosity data with $\left\langle R_{\mathrm{g}}^{2}\right\rangle_{0}$, in theta condition. Accordingly, $K_{\theta}$ and $C_{\infty}$ are related by the following equation ${ }^{29}$ :

$$
C_{\infty}=\left(\frac{K_{\theta}}{\phi}\right)^{3 / 2} \times \frac{(m / 2)}{l^{2}}
$$

where $\phi$ is Flory's viscosity constant $\left(\phi=2.5 \times 10^{23}\right)$.

Evaluating chain stiffness of butyl polymers outstanding remarks can be made. $\mathrm{P} t \mathrm{BA}$ has the most rigid chain (11.6) when compared with the others of the same family. This was already expected since MHS exponential constant lead to conclude that $\mathrm{P} t \mathrm{BA}$ was the least soluble in a given solvent. However, PiBA exhibits the lowest chain stiffness (6.58) followed by $\mathrm{P} n \mathrm{BA}$ (9.24). At 

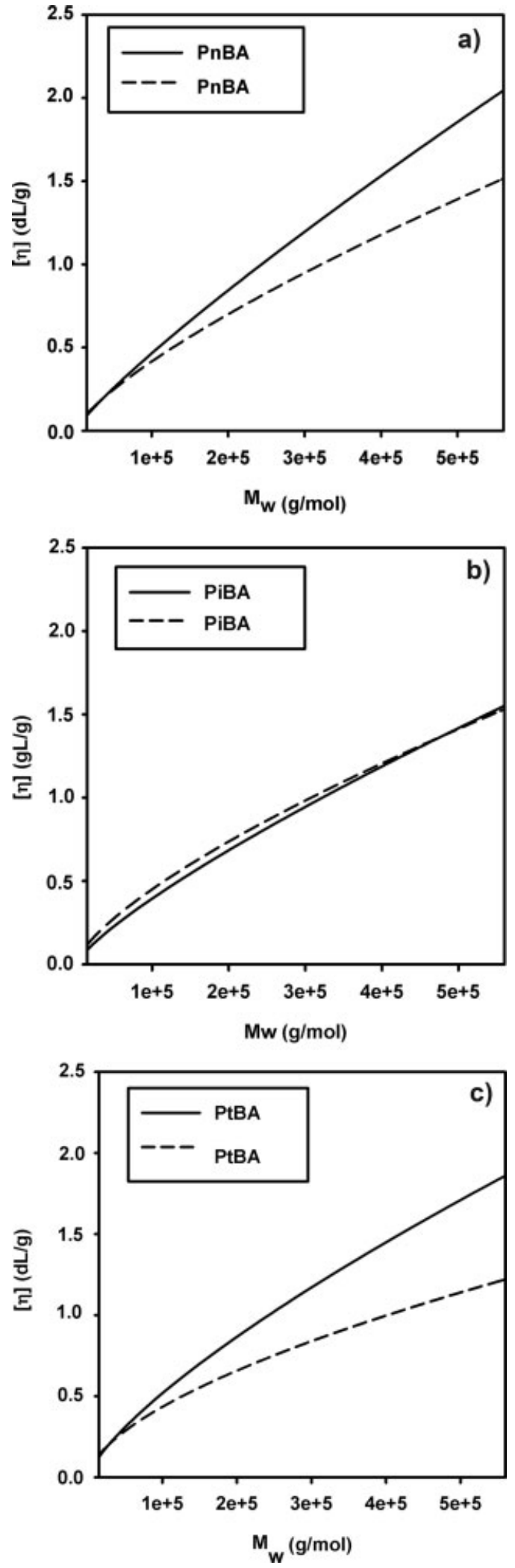

Figure 5. Viscosity of PBA isomers prepared by SET and by FRP: (a) PnBA, (b) PiBA, and (c) PtBA (dash line - prepared by FRP; solid line - prepared by LRP). first sight, it would be expected that $\mathrm{P} n \mathrm{BA}$ would have smaller value given this tendency observed in MHS constants. Nevertheless, perhaps some other conformational factors influence this observation and should be investigated in more detail.

Comparable Structural Analysis of the PnBA, PiBA, and PtBA by $500 \mathrm{MHz}{ }^{1} \mathrm{H}$ NMR Spectroscopy

Figure 6(a) shows the ${ }^{1} \mathrm{H}$ NMR spectrum of the $\operatorname{PnBA}\left(M_{\mathrm{n}}=52,340\right)$; where $(*)$ represents a fragment around 4.5-5.5 ppm of $\mathrm{P} n \mathrm{BA}$ of $M_{\mathrm{n}}=8520$ ). Figure 6(b) demonstrates the spectrum of $\mathrm{P} i \mathrm{BA}$ $\left(M_{\mathrm{n}}=45,300\right)$, where $\left.{ }^{* *}\right)$ represents a fragment around 4.5-5.5 ppm of PiBA of $M_{\mathrm{n}}=9540$. Figure 6(c) shows the proton NMR spectrum of $\mathrm{P} t \mathrm{BA}$ $\left(M_{\mathrm{n}}=50,200\right)$, where $(* * *)$ represents a fragment around 4.5-5.5 ppm of $\mathrm{P} t \mathrm{BA}$ of $M_{\mathrm{n}}=7450$. All the polymers were obtained by SET-DTLRP at $35{ }^{\circ} \mathrm{C}$. Figure 6(a) demonstrates active chain end at $\mathrm{H}_{\mathrm{d}}$ at $4.35 \mathrm{ppm}$, while the spectrum of low $M_{\mathrm{n}} \mathrm{P} n \mathrm{BA}$ (*) also contains the terminal iodoform residue $\mathrm{H}_{\mathrm{i}}$ at $5.0 \mathrm{ppm}$. The internal iodoform residue $\mathrm{H}_{\mathrm{a}}$ reveals a small signal at $4.2 \mathrm{ppm}$. The resonances of butyl fragment $\mathrm{O}-\mathrm{CH}_{2}(\mathrm{e})-\mathrm{CH}_{2}(\mathrm{f})-\mathrm{CH}_{2}(\mathrm{~g})-$ $\mathrm{CH}_{3}(\mathrm{~h})$ signal at $4.05\left(\mathrm{H}_{\mathrm{e}}\right), 1.6\left(\mathrm{H}_{\mathrm{f}}\right), 1.4\left(\mathrm{H}_{\mathrm{g}}\right)$, and $0.9\left(\mathrm{H}_{\mathrm{h}}\right) \mathrm{ppm}$, respectively. The signals of the methine protons of main $\mathrm{P} n \mathrm{BA}$ chain $\left(\mathrm{H}_{\mathrm{c}}\right)$ are situated at $2.3 \mathrm{ppm}$. The main $\mathrm{P} n \mathrm{BA}$ chain methylene protons $\left(\mathrm{H}_{\mathrm{b}}\right)$ reveals both meso $(\mathrm{b}-\mathrm{m})(1.9$, $1.5-1.4 \mathrm{ppm})$ and recemo (b-r) (1.6 ppm, overlapped with $\mathrm{H}_{\mathrm{f}}$ ) protons. PnBA tacticity measurement resulted in the syndiotactic content of $55 \%$.

Proton NMR spectrum of PiBA [Fig. 6(b)] demonstrates active chain-end $\mathrm{H}_{\mathrm{d}}$ at $4.3 \mathrm{ppm}$. Low $M_{\mathrm{n}}$ PiBA spectrum (**) also reveals the terminal iodoform residue $\mathrm{H}_{\mathrm{i}}$ at $4.95 \mathrm{ppm}$. The internal iodoform residue $\mathrm{H}_{\mathrm{a}}$ shows resonances at $4.15 \mathrm{ppm}$. The isobutyl fragment $\mathrm{O}-\mathrm{CH}_{2}(\mathrm{e})-\mathrm{CH}(\mathrm{l})-$ $\left(\mathrm{CH}_{3}\right)_{2}(\mathrm{~h})$ shows the resonances of $\mathrm{H}_{\mathrm{e}}$ at $3.8, \mathrm{H}_{\mathrm{l}}$ at 1.85 (overlapped with the signal of meso-methylene of the main chain) and $\mathrm{H}_{\mathrm{h}}$ at $0.9 \mathrm{ppm}$, respectively. The main chain is presented by methines $\mathrm{H}_{\mathrm{c}}(2.3$ ppm) and $\mathrm{H}_{\mathrm{j}}(2.7 \mathrm{ppm})$ as well as methylene protons $\mathrm{H}_{\mathrm{b}}$ and $\mathrm{H}_{\mathrm{k}}$ : strong ones at 1.9 (overlapped with $\left.\mathrm{H}_{\mathrm{l}}\right), 1.5-1.4\left(\mathrm{H}_{\mathrm{b}-m}\right)$, and $1.6 \mathrm{ppm}\left(\mathrm{H}_{\mathrm{b}-r}\right)$, and weak ones at $2.05,1.5 \mathrm{ppm}\left(\mathrm{H}_{\mathrm{k}-m}\right)$, and $1.7 \mathrm{ppm}\left(\mathrm{H}_{\mathrm{k}-\mathrm{r}}\right)$. PiBA tacticity measurement resulted in the same syndiotactic content as for PnBA, namely $55 \%$.

The proton NMR spectrum of $\mathrm{P} t \mathrm{BA}$ is shown in Figure 6(c). In this case, the bulky tert-butyl substituents is the reason of two signals belonging meso and racemo active chain ends $\mathrm{H}_{\mathrm{d}}$ at 4.25 and 4.22 ppm. The internal iodoform residue $\mathrm{H}_{\mathrm{a}}$ shows 
c)<smiles>CC(C)C[C@H](CC(C)C(=O)OC(C)(C)C)C(C)C(=O)OC(C)(C)C</smiles>
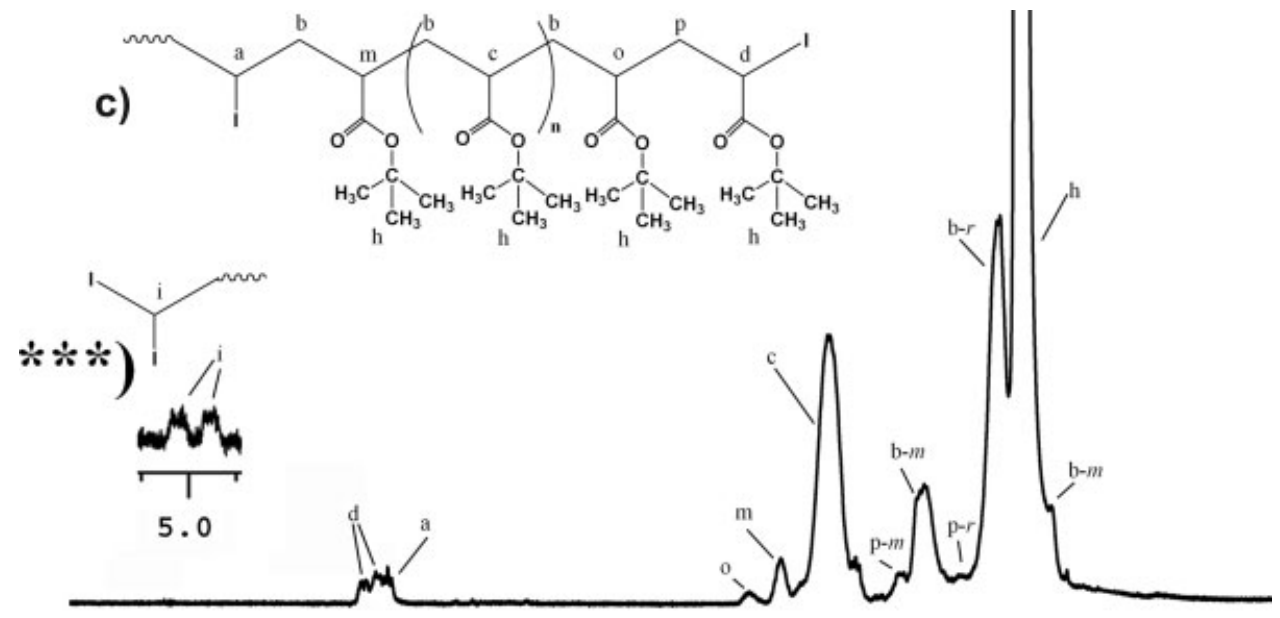

b)
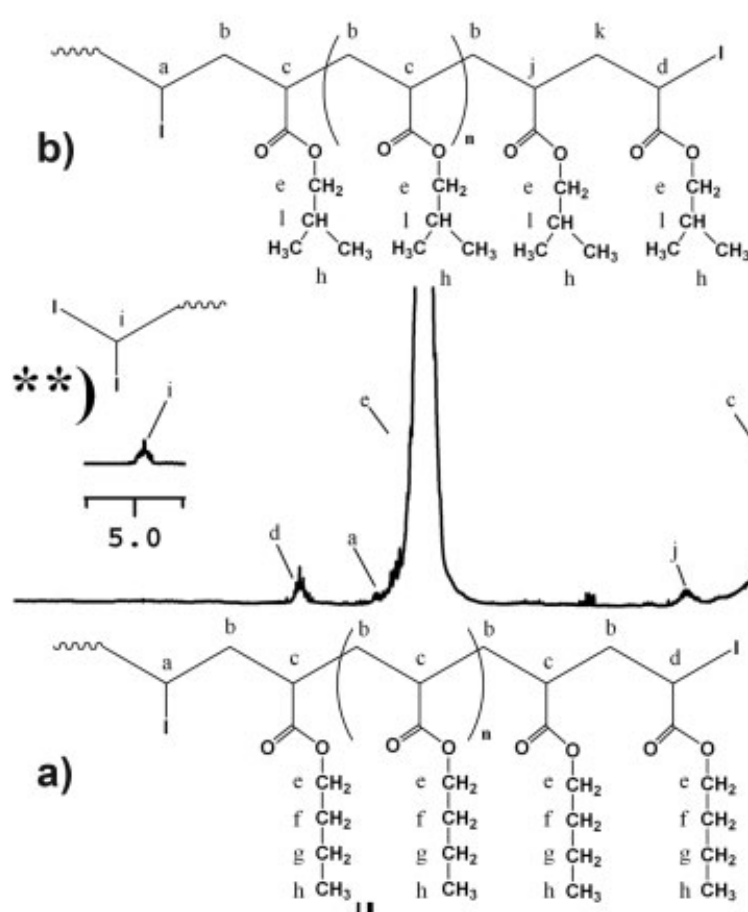

h $\mathrm{CH}_{3}$

h $\mathrm{CH}_{3}$

h $\mathrm{CH}_{3}$

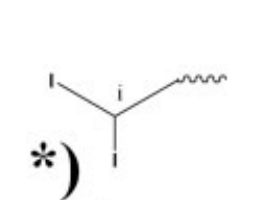

*)
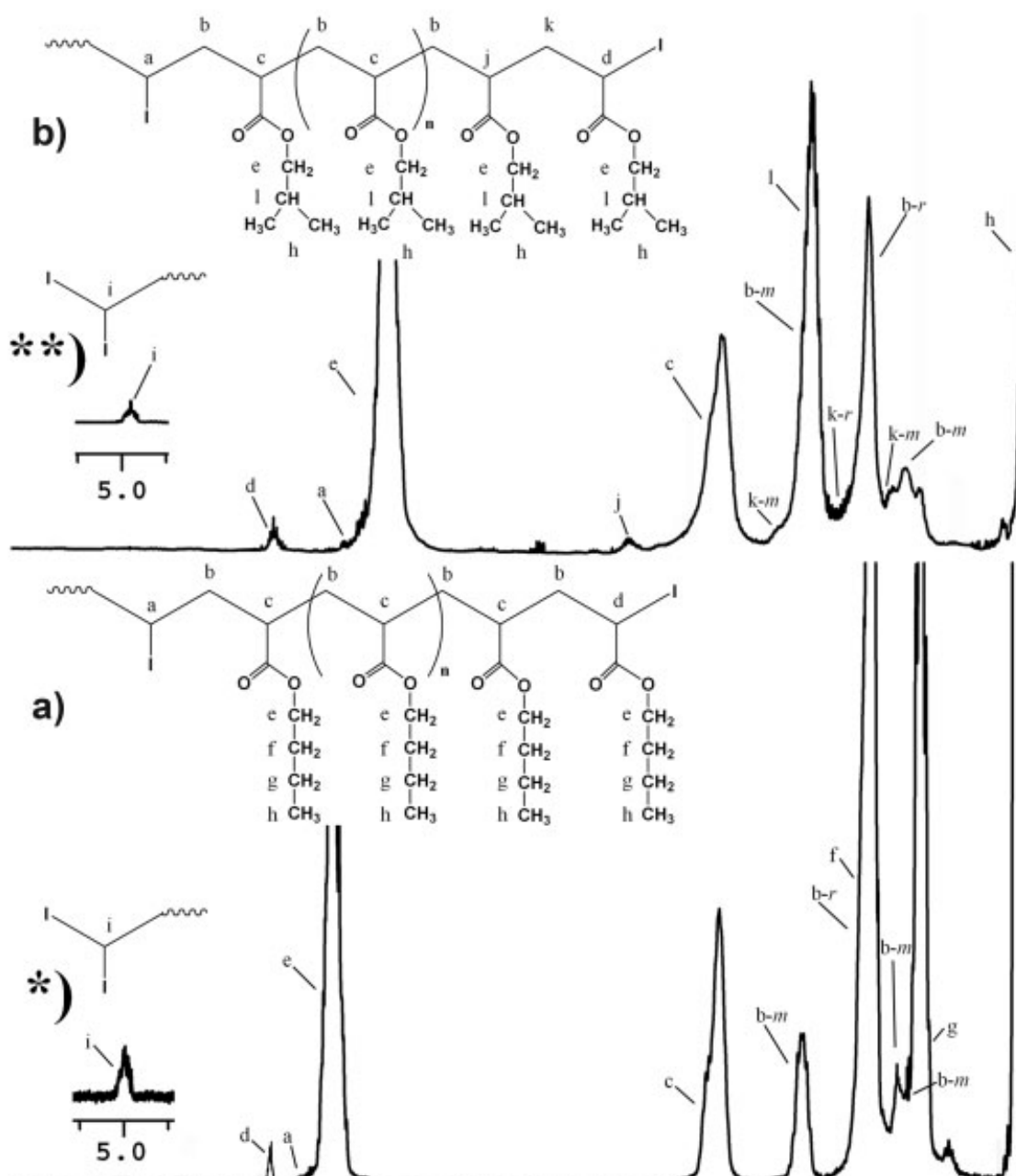

1
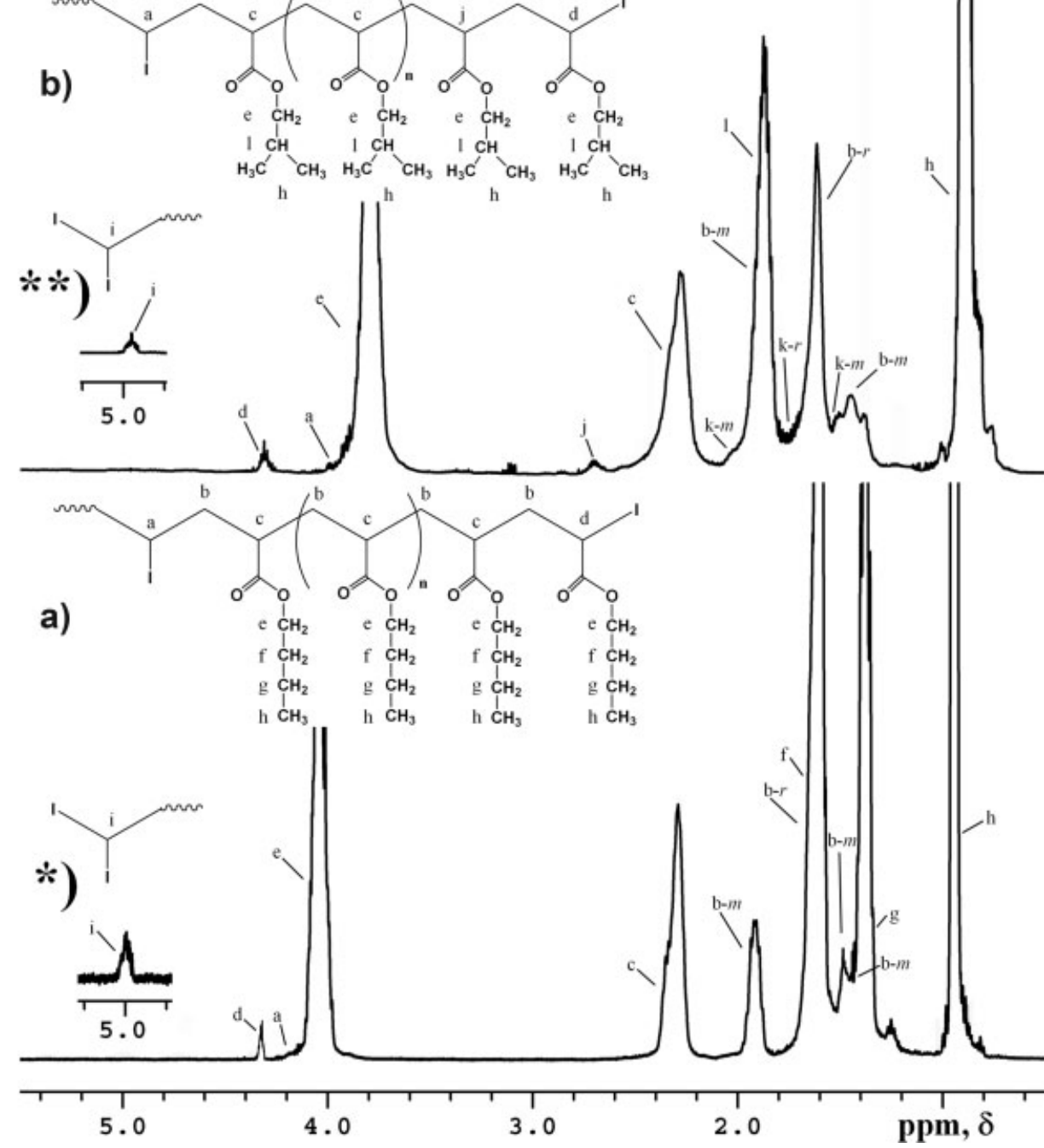

Figure 6. $500 \mathrm{MHz}{ }^{1} \mathrm{H}$ NMR spectra in $\mathrm{CDCl}_{3}$ of obtained $\alpha, \omega$-di(iodo) PBA isomers prepared by SET/DTLRP at $35^{\circ} \mathrm{C}$.

resonances at $4.19 \mathrm{ppm}$. Because of the $t$-butyl bulkiness, even the prochiral iodoform terminal residue in low $M_{\mathrm{n}} \mathrm{P} t \mathrm{BA}$ sample (***) reveals two resonances at 4.95 and 5.05 ppm. $t$-Butyl protons $\mathrm{H}_{\mathrm{h}}$ signal at $1.55 \mathrm{ppm}$. The main-chain methine protons are presented by a strong signal of $\mathrm{H}_{\mathrm{c}}$ at $2.35 \mathrm{ppm}$ and two 
weak signals at $2.7 \mathrm{ppm}\left(\mathrm{H}_{\mathrm{o}}\right)$ and $2.55 \mathrm{ppm}\left(\mathrm{H}_{\mathrm{m}}\right)$. $\mathrm{P} t \mathrm{BA}$ main polymer chain methylene protons reveal strong resonances at 2.0, 1.5-1.4 ppm $\left(\mathrm{H}_{\mathrm{b}-m}\right)$, and $1.65 \mathrm{ppm}\left(\mathrm{H}_{\mathrm{b}-r}\right)$ along with the weak signals of $\mathrm{H}_{\mathrm{p}}$ at $2.05 \mathrm{ppm}$ (the downfield signal of $\mathrm{H}_{\mathrm{p}-m}$, the upfield $\mathrm{H}_{\mathrm{p}-m}$ signal is overlapped with $\mathrm{H}_{\mathrm{h}}$ and $\mathrm{H}_{\mathrm{b}-m}$ strong signals) and $1.8 \mathrm{ppm}\left(\mathrm{H}_{\mathrm{p}-r}\right)$.

The syndiotacticity of $\mathrm{P} t \mathrm{BA}$ is $58 \%$. This is higher than the syndioctacticity of $\mathrm{P} n \mathrm{BA}, \mathrm{P} i \mathrm{BA}$ (this study), and PEtA-55\%, ${ }^{30}$ but lower than the syndioctacticity of poly(lauryl acrlylate) $(75 \%){ }^{31}$ By this mean, it was shown that butyl and isobutyl groups does not influence tacticity much, as $\mathrm{P} n \mathrm{BA}$ and $\mathrm{P} i \mathrm{BA}$ syndiotactic content is the same as the one of polyethylacrylate. ${ }^{30}$

The bulkier $t$-butyl group does influence tacticity, but not so much as a long lauryl $\left(n \mathrm{C}_{12} \mathrm{H}_{25}\right)$ group. $^{31}$

\section{CONCLUSIONS}

The results presented in this work revealed the influence of the isomeric structure of butyl acrylates on the SET-DTLRP in aqueous medium as well as the properties of the polymers obtained. The regularities are found for polymerization rates $(t \mathrm{BA}>n$ $\mathrm{BA}>i \mathrm{BA})$, polymer stiffness ( $\mathrm{P} t \mathrm{BA}>\mathrm{P} n \mathrm{BA}>\mathrm{P} i \mathrm{BA})$, syndiotacticity $(\mathrm{P} t \mathrm{BA}>\mathrm{P} n \mathrm{BA}=\mathrm{P} i \mathrm{BA})$, and intrinsic viscosity $(\mathrm{P} i \mathrm{BA}>\mathrm{P} t \mathrm{BA}>\mathrm{P} n \mathrm{BA})$. This information is of prime importance in way to tailor the properties of the new materials prepared from the telechelic macroinitiators synthesized.

\section{REFERENCES AND NOTES}

1. Perrier, S.; Takolpuckdee, P. J Polym Sci Part A: Polym Chem 2005, 43, 5347-5393.

2. Fukuda, T.; Terauchi, T.; Goto, A.; Ohno, K.; Tsuji, Y.; Miyamoto, T. Macromolecules 1996, 29, 6393-6398.

3. Wang, J.-S.; Matyjaszewski, K. Macromolecules 1995, 28, 7901-7910.

4. Percec, V.; Popov, A. V.; Ramirez-Castilho, E.; Coelho, J. F. J.; Hinojosa-Falcon, L. A. J Polym Sci Part A: Polym Chem 2004, 42, 6267-6282.

5. Percec, V.; Popov, A. V.; Ramirez-Castilho, E.; Weichold, O. J. J Polym Sci Part A: Polym Chem 2003, 41, 3283-3299.

6. Percec, V.; Popov, A. V.; Ramirez-Castilho, E.; Monteiro, M.; Barboiu, B.; Weichold, O.; Asandei, A. D.; Mitchell, C. M. J Am Chem Soc 2002, 124, 4940-4941.

7. Percec, V.; Guliashvili, T.; Popov, A. V.; RamirezCastilho, E. J Polym Sci Part A: Polym Chem 2005, 43, 1478-1486.

8. Percec, V.; Guliashvili, T.; Popov, A. V. J Polym Sci Part A: Polym Chem 2005, 43, 1948-1954.

Journal of Polymer Science: Part A: Polymer Chemistry DOI $10.1002 /$ pola
9. Percec, V.; Ramirez-Castilho, E.; Popov, A. V.; Hinojosa-Falcon, L. A.; Guliashvili, T. J Polym Sci Part A: Polym Chem 2005, 43, 2178-2184.

10. Percec, V.; Popov, A. V.; Ramirez-Castilho, E.; Weichold, O. J Polym Sci Part A: Polym Chem 2004, 42, 6364-6374.

11. Coelho, J. F. J.; Silva, A. M. F. P.; Popov, A. V.; Percec, V.; Abreu, M. V.; Gonçalves, P. M. O. F.; Gil, M. H. J Polym Sci Part A: Polym Chem 2006, 44, 2809-2825.

12. Coelho, J. F. J.; Silva, A. M. F. P.; Popov, A. V.; Percec, V.; Abreu, M. V.; Gonçalves, P. M. O. F.; Gil, M. H. J Polym Sci Part A: Polym Chem 2006, 44, 3001-3008.

13. Muñoz-Bonilla, A.; Cerrada, M. L.; García-Fernández, M. J Polym Sci Part A: Polym Chem 2005, 43, 4828-4837.

14. Vlcek, P.; Cadová, E.; Kriz, J.; Latalová, P.; Janata, M.; Toman, L.; Massar, B. Polymer 2005, 46, 4991-5000.

15. Ibrahim, K.; Löfgren, B.; Seppäla, J. Eur Polym J 2003, 39, 2005-2010.

16. Bussels, R.; Bergaman-Gottgens, C.; Klumperman, B.; Meuldijk, J.; Koning, C. J Polym Sci Part A: Polym Chem 2006, 44, 6419-6434.

17. Bussels, R.; Bergaman-Gottgens, C.; Meuldijk, J.; Koning, C. Polymer 2005, 46, 8546-8554.

18. Coelho, M. R. G.; Gil, R. A. S.; Tavares, M. I. B. Polym Test 1996, 15, 485-490.

19. Coelho, J. F. J.; Carreira, M.; Popov, A. V.; Gonçalves, P. M. O. F.; Gil, M. H. J Vinyl Add Tech 2006, 12, 156-165.

20. Coelho, J. F. J.; Carreira, M.; Popov, A. V.; Gonçalves, P. M. O. F.; Gil, M. H. Eur Polym J 2006, 42, 2313-2319.

21. Tabuchi, M.; Kawauchi, T.; Kitayama, T.; Hatada, K. Polymer 2002, 43, 7185-7190.

22. Hishra, H. K.; Yagci, Y. Handbook of Radical Vinyl Polymerization; Marcel Dekker: New York, 1998.

23. Matyjaszewski, K.; Gaynor, S.; Wang, J.-S. Macromolecules 1995, 28, 2093-2095.

24. Qiu, J.; Charleux, B.; Matyjaszewski, K. Prog Polym Sci 2001, 26, 2083-2134.

25. Ravve, A. Principles of Polymer Chemistry; Kluwer Academic/Plenum Publishers: New York, 2000.

26. Teraoka, I. Polymer Solutions: An Introduction to Physical Properties; Wiley: New York, 2002.

27. Penzel, R.; Goetz, N. Angew Makromol Chem 1990, 78, 191-200.

28. Jackson, C.; Chen, Y.-J.; Mays, J. W. J Appl Polym Sci 1996, 61, 865-874.

29. Gómez, C.; Navarro, A.; Manzanares, P.; Horta, A.; Carbonell, J. V. Carbohydr Polym 1997, 32, 17-22.

30. Coelho, J. F. J.; Carvalho, E. Y.; Marques, D. S.; Percec, V.; Popov, A. V.; Gonçalves, P. M. O. F.; Gil, M. H. J Polym Sci Part A: Polym Chem 2007, 42, 421-432.

31. Coelho, J. F. J.; Carvalho, E. Y.; Marques, D. S.; Popov, A. V.; Gonçalves, P. M. O. F.; Gil, M. H. Macromol Chem Phys 2007, 208, 1218-1227. 